\title{
HACIÉNDONOS HUMANOS. ANÁLISIS DE UNA EXHIBICIÓN CIENTÍFICA EN ARGENTINA
}

\author{
BECOMING HUMAN: \\ ANALYSIS OF A SCIENTIFIC EXHIBITION IN ARGENTINA \\ María Eugenia Conforti ${ }^{1}$, María Gabriela Chaparro ${ }^{1}$, Mercedes Mariano ${ }^{1}$ y \\ J. Carlos Díez Fernández-Lomana ${ }^{2}$
}

\begin{abstract}
En este artículo se analiza la exhibición "Evolución: Haciéndonos Humanos” presentada en la megaferia de ciencias de Argentina, TECNÓPOLIS, desde la perspectiva de la comunicación pública de la ciencia. Para su contextualización se realizan algunas apreciaciones generales acerca del surgimiento de las exposiciones de ciencias y su vinculación con los Estados nacionales y el evolucionismo. El abordaje metodológico se basó en los estudios de público que combinan el análisis del guión y la opinión de los visitantes. Este relevamiento se complementó con entrevistas a diferentes actores sociales involucrados en la organización de la muestra, lo que posibilitó un abordaje integral acerca de los procesos de comunicación que esta propone. A partir de los resultados se señalan fortalezas y debilidades de la misma y plantean cuestiones que podrían contribuir a la discusión de la comunicación de contenidos científicos en diferentes contextos.
\end{abstract}

Palabras claves: comunicación pública de la ciencia; evolución humana; estudios de público; TECNÓPOLIS; Argentina.

In this article, the exhibition "Evolution: Making us Human" presented in the TECNOPOLIS science megafair in Argentina is analyzed from the perspective of the public communication of science. To contextualize it, a general assessment about the rise of science fairs and their link with the state and evolutionism is made. The methodological approach was based on studies that combine public script analysis and the opinion of visitors. This survey was supplemented by interviews with various stakeholders involved in the organization of the exhibition, enabling a comprehensive analysis of its communication processes. From the results, strengths and weaknesses are identified and they raise issues that could contribute to the discussion of the communication of scientific content in different contexts.

Key words: Public communication of science, human evolution, public studies, TECNOPOLIS, Argentina.

En el presente siglo, los países latinoamericanos han posicionado a la Ciencia y la Tecnología (en adelante CyT) como una de las principales herramientas para el desarrollo de sus países, así lo afirma un informe de la Organización de las Naciones Unidas para la Educación, la Ciencia y la Cultura (UNESCO) (Fernández Polcuch et al. 2016). Concretamente en Argentina, las políticas públicas emprendidas desde el 2003 buscaron transformar el país en una nación que combinara el crecimiento económico con justicia social. En este contexto, tuvieron un papel fundamental la educación, la ciencia y la tecnología, convirtiéndolas en una política de Estado (Albornoz y Gordon 2011; Politis y Curtoni 2011). Por esta razón, y en cumplimiento de la Ley 25.467 de Ciencia, Tecnología e Innovación, se elaboraron planificaciones estratégicas a largo plazo $^{1}$, cuyas prioridades fueron el incremento de la producción de conocimientos científicos y tecnológicos, la formación de recursos humanos, la incorporación de procesos de innovación a las estructuras institucionales y la democratización de los conocimientos (Albornoz y Gordon 2011).

En sintonía con estas políticas estatales impulsadas en Argentina, en 2007 se creó el Ministerio de Ciencia, Tecnología e Innovación Productiva (en adelante MINCyT), donde la promoción y divulgación de la ciencia es uno de sus objetivos para que "los ciudadanos sean capaces de entender cómo funciona la ciencia y cómo interactúa con su vida cotidiana, y para que sean capaces de participar conscientemente en decisiones que

1 Consejo Nacional de Investigaciones Científicas y Técnicas (CONICET). Instituto de Investigaciones Arqueológicas y Paleontológicas del Cuaternario Pampeano INCUAPA (Unidad Ejecutora CONICET-UNICEN). Facultad de Ciencias Sociales, Universidad Nacional del Centro de la Provincia de Buenos Aires, Olavarría, Argentina. meconfor@ soc.unicen.edu.ar; chaparro@soc.unicen.edu.ar; mercedes.mariano@gmail.com

2 Laboratorio de Prehistoria, Universidad de Burgos, Burgos, España. Clomana@ubu.es

Recibido: noviembre 2015. Aceptado: septiembre 2016.

http://dx.doi.org/10.4067/S0717-73562016005000038. Publicado en línea: 05-diciembre-2016 
afecten a la política de ciencia y tecnología". Para la consecución de esta meta, entre múltiples acciones, se destaca el Programa Nacional de Popularización de la Ciencia y la Tecnología. Paralelamente, en 2010 se realizaron una serie de eventos por los festejos del Bicentenario del Primer Gobierno Patrio y se comenzó a gestar en la Secretaría General de la Presidencia, a través de la Unidad Ejecutora Bicentenario, la idea de una gran exposición científica. En este contexto surge TECNÓPOLIS, megaferia sobre ciencia, tecnología, industria y arte, de acceso libre y gratuito, con 50 hectáreas de extensión, ubicado en el área metropolitana de la provincia de Buenos Aires, Argentina (Figura 1).

En este punto es necesario aclarar que los fundamentos que postulan que la ciencia es uno de los principales pilares para el desarrollo, ha sido la justificación que promovió el fomento de la CyT, plasmado en variadas políticas públicas concretas en Argentina. Este tema es, en sí mismo, materia de discusión y análisis y en este trabajo es utilizado como un marco para entender la lógica que dio origen a TECNÓPOLIS y no pretende constituirse en un punto a debatir en profundidad. En el presente artículo solo se desarrolla el contexto histórico de surgimiento de esta concepción acerca de la ciencia.

TECNOPÓLIS abre por primera vez sus puertas el 2011 bajo el lema "Decir presente, mirando al futuro" 2 . Su objetivo principal consiste en democratizar la ciencia a través de la conjunción del sector público (universidades, organismos de investigación y desarrollo y organizaciones sociales) y el privado. En el 2013, en su tercera edición, se incorpora por primera vez, entre las múltiples propuestas, una exhibición denominada "Evolución: Haciéndonos Humanos" (en adelante Evolución).

A partir de todo lo expuesto, se realizan algunas apreciaciones generales acerca del surgimiento de las exposiciones de ciencias y su vinculación con los Estados nacionales y el evolucionismo, para luego analizar puntualmente la muestra "Evolución", su mensaje y las opiniones y valoraciones que el público

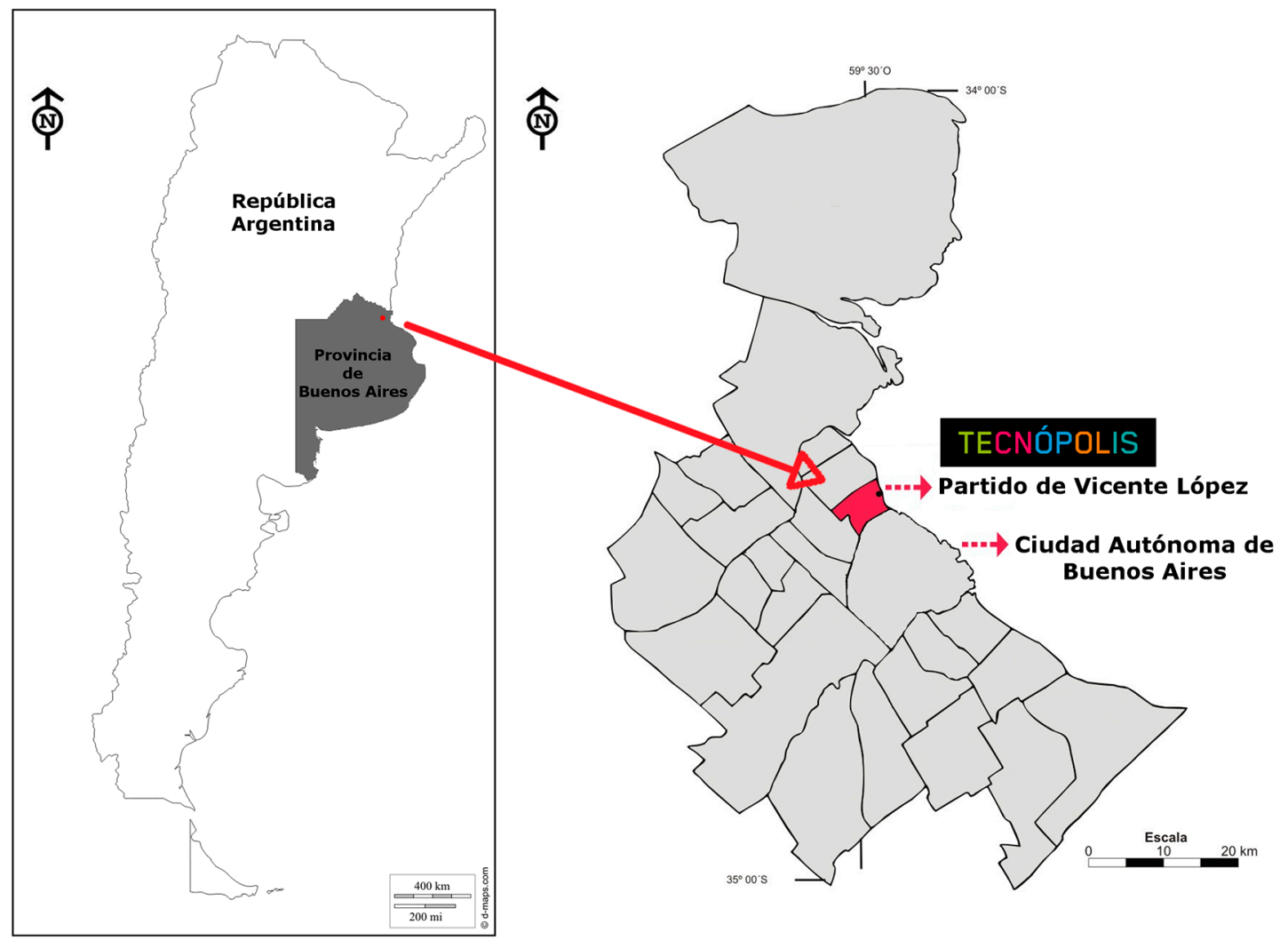

Figura 1. Referencia ubicación de TECNÓPOLIS.

TECNOPOLIS location reference. 
construye en relación a la misma, entendiéndola como una estrategia de comunicación pública de la ciencia (en adelante CPC).

\section{"Evolución” y la Comunicación Pública de la Ciencia}

Este trabajo analiza la exhibición "Evolución"3 presentada en 2014 (por segundo año consecutivo), rediseñada, cuya superficie ocupó $4.000 \mathrm{~m}^{2}(2.000$ $\mathrm{m}^{2}$ de intervención al aire libre y $2.000 \mathrm{~m}^{2}$ cubiertos), distribuidos en tres pabellones (Figura 2). Visitada por 373.648 personas $^{4}$, realizada a través de un convenio entre organismos argentinos y españoles: por Argentina, el MINCyT, la Fundación de Historia Natural Félix de Azara y por España, el Museo de la Evolución Humana de Burgos, la Universidad de Burgos, la Fundación Atapuerca y la Junta de Castilla y León ${ }^{5}$. Esta asociación responde a que la exhibición "Evolución" planteó como desafío inicial la escasez de fósiles humanos originales en Argentina, y por ello se decidió establecer esta alianza internacional, mientras que el aporte local en cuanto a piezas originales consistió en restos de fauna extinta, patrimonio rico y único provisto por diversas instituciones (Tomás Ameigeiras, comunicación personal, 2014).

Este trabajo estudia la muestra como un caso particular de CPC, disciplina que se centra en analizar las diversas actividades que promueven la democratización de conocimientos científicos dirigidos a un conjunto de personas no especializadas (Fayard 2004). En este sentido, que no es posible concebir la ciencia sin considerar al público, su contexto y las reacciones sociales que promueve (Einsiedel 2007).

No obstante, el mayor desafío actual de la CPC consiste en incorporar la evaluación de resultados para constatar si el proceso comunicativo realizado fue capaz de generar transformaciones en los involucrados (Von Foerster 1981) y así establecer su alcance (Neresini y Pellegrini 2008).

La CPC puede presentarse en múltiples formatos, uno de ellos puede ser a través de la museología (Gregory y Miller 1998), que implica la exhibición de contenidos científicos en museos o en otros espacios, como los parques temáticos diseñados para tales fines. Si se considera que las exposiciones tienen como principal objetivo la comunicación (García Blanco 1999), se vuelve pertinente analizar el vehículo por el cual el visitante construye conocimiento. Esto implica estudiar la forma en que el público entrelaza su experiencia con objetos, textos y distintos dispositivos en un espacio en particular (Alonso Fernández y García Fernández 1999; Hernández Hernández 1998). En términos de García Blanco (1999), la exposición científica es una forma de comunicación que mediará entre los visitantes y los objetos expuestos para facilitar su comprensión (Shärer 2000).

La complejidad de las exhibiciones sobre la evolución humana, ha sido abordada por diversos investigadores, poniendo el énfasis en aspectos tales como el diseño y la manera en que el contenido es presentado (Endersby 1997), las motivaciones y la comprensión de conceptos (MacFadden 2008) y la aceptación o no de las teorías evolutivas frente a las creacionistas (Pawlukiewicz et al. 1990; Stein y Storksdieck 2005). Estos trabajos se realizan sobre exhibiciones de museos, es decir, contextos diferentes a TECNÓPOLIS, pero apuntan a determinar cuál es la mejor manera de facilitar el aprendizaje y proponer nuevos diseños de exhibiciones para abrir el camino a la comprensión pública de las ideas evolutivas básicas (Spiegel et al. 2006).

\section{Ciencia, Estado y Evolucionismo}

En la segunda mitad del siglo XIX en Europa surgen las "Exposiciones Universales", internacionales y abiertas a todo público, donde se exponen los últimos logros tecnológicos, con el objetivo de visibilizar "los avances" de las ciencias (Laumonnier 1993). López Ocon (2002) hace una recopilación de los numerosos trabajos que las han abordado desde sus múltiples implicancias, como sitios donde se desplegaron los poderíos estatales, lugares de iniciación al progreso científico e industrial y espacios aleccionadores con poder divulgativo y recreativo. Para este autor, las exposiciones universales

contribuyeron a ser agentes de ese doble proceso de mundialización y mundanización de la ciencia. En primer lugar porque actuaron como lugares de transferencia de ciencia aplicada hacia los países que no habían iniciado la revolución tecnológica y constituyeron redes internacionales de documentación científica y técnica (...). A su vez fueron vectores de su mundanización porque fueron concebidas como grandes 


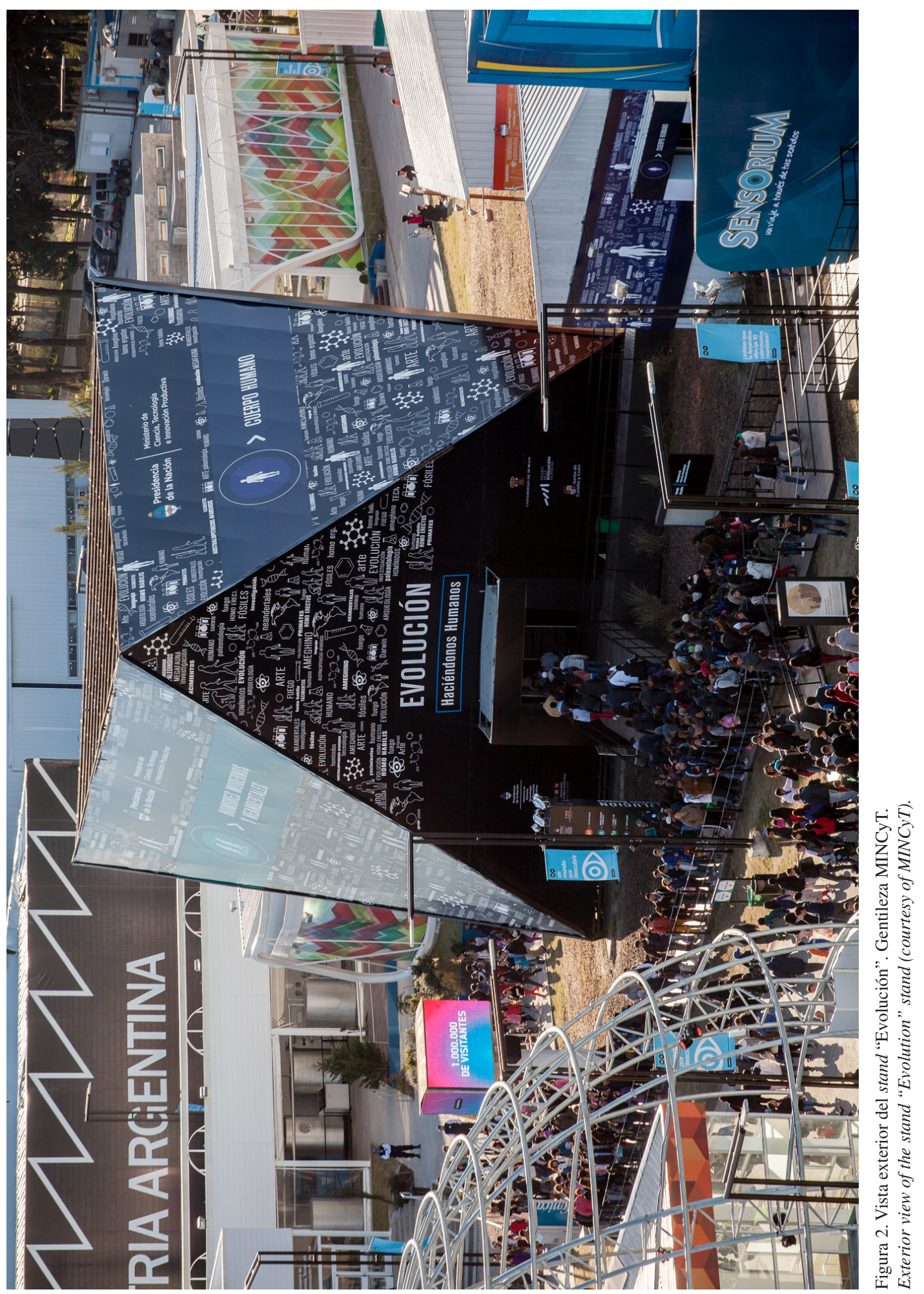


instrumentos pedagógicos para suplir deficiencias del sistema educativo, y se comportaron entonces como vehículos de afirmación de la revolución técnica (López Ocon 2002:108).

Se puede plantear en este sentido que TECNÓPOLIS, aunque impulsada actualmente por un Estado particular (latinoamericano), comparte muchos de los propósitos que adquirieron estas grandes exposiciones, por ejemplo, la promoción activa de la CyT como motor para el desarrollo del país y la democratización de la ciencia a partir de la creación de redes interinstitucionales (entre el sector público y privado) para alcanzar dichos fines.

Al hablar de las exposiciones del siglo XIX, es importante mencionar que las mismas favorecieron y fortalecieron el colonialismo y el imperialismo de la época de la mano de la naciente antropología. Quizás la definición más elocuente es que actuaron como teatros donde se forjó "el imperio de la ciencia y la ciencia del imperio" (López Ocon 2002:108). Un ejemplo paradigmático es la Exposición Universal de París de 1889 de los representantes vivos de diferentes regiones colonizadas, lo que permitía ejemplificar, desde la perspectiva europea, su inferioridad racial y el progreso inexorable que culminaba en la superioridad occidental. Cabe recordar que en esas ferias, la evolución humana se presentaba como el relato que explicaba y fundamentaba nuestra existencia (Laumounier 1993).

En este marco, hablar de exhibiciones del siglo XIX implica necesariamente hacer referencia a los museos, como aquellos espacios dotados de una fuerte significación simbólica, productos de la modernidad donde se expresa la forma de organización de las naciones y del modo que los sectores dominantes representaron la historia de las mismas (Althusser 1971; Huyssen 2002; Merriman 1991). Es innegable su función legitimadora de las relaciones de poder (Bourdieu y Darbel 2004; Foucault 1996; Podgorny y Lopes 2008) a través de la reproducción del mito que posiciona al occidental en la cúspide del progreso (Merriman 2000; Preucel y Hodder 1996).

Durante la primera mitad del siglo XX frente a las guerras y genocidios, las ideas sobre el progreso de las naciones, la ciencia como motor del desarrollo y la superioridad occidental, fueron cuestionadas y se vieron relegadas. Sin embargo, en la postguerra la reconstrucción del mundo volvió a justificarse con el evolucionismo cultural, esta vez como neoevolucionismo y por parte de los antropólogos estadounidenses. Un ejemplo de ello es la teoría explicativa del progreso humano que permite naturalizar las condiciones por las cuales ese país se convirtió en la gran potencia mundial dominante en esta nueva era (Trigger 1989).

En la actualidad no todos los museos cargan con su sello de origen y ello se debe a diferentes cuestiones no solo ligadas a las transformaciones de las sociedades globalizadas, sino también a la autorreflexión de la museología acerca de las múltiples implicancias sociales de sus intervenciones y a las críticas recibidas desde diferentes disciplinas, donde no solo se pone en crisis la neutralidad de los discursos y los vínculos con el poder hegemónico, sino también la primacía que habían adquirido los objetos y las colecciones por sobre el público (Durrans 1988; Laumounier 1993; Vergo 1989). Desde hace ya varios años, en estos espacios se puede llamar a la reflexión y permitir (re)lecturas e instancias de resistencia y de construcción de alternativas (Alegría Luicime 2004) como los museos comunitarios y la incorporación de otras voces en sus guiones (Hernández Hernández 2015; Merriman 2000; Pérez Gollán y Dujovne 1996; Rinesi 2011).

\section{Metodología}

La perspectiva metodológica de este trabajo corresponde a "estudios de público", herramienta utilizada para evaluar la experiencia en una exposición que incluye el análisis de exposiciones, de visitantes reales y potenciales, de diseños, así como la evaluación de actividades, servicios generales y de atención al público (Pérez Santos 2000). Para ello se emplea una combinación de técnicas como las entrevistas, las encuestas y la observación (Reca 2016).

Según el modelo interactivo propuesto por Falk y Dierking (2000), durante la visita a una exposición se produce una interacción de tres contextos del visitante: personal (sus intereses, motivaciones e inquietudes); social (contacto con otros usuarios o con el personal de la exposición) y físico (arquitectónicos, vitrinas, iluminación, etc.) que inciden en su experiencia de visita. Para su evaluación se pueden emplear variables de tipo demográfico (permiten acceder a información sobre el perfil de los visitantes), sociales (hábitos, tradiciones), cognitivas (comprensión de los contenidos) y valorativas (útiles para conocer el grado de satisfacción). Su utilidad es cada vez 
más revalorada, ya que sus resultados se vuelven un insumo de retroalimentación y beneficio para mejorar el proceso comunicativo de las exhibiciones, a la vez que es una herramienta de análisis crítico para discutir y realizar aportes al campo.

En el caso de la exhibición "Evolución" se recurrió en primer lugar al análisis de su mensaje mediante el estudio de su guión museográfico. Para ello se realizaron observaciones directas de la misma, al acceso, al circuito, a la cartelería, a los dispositivos expuestos y se tomó en consideración los efectos, la iluminación, los colores empleados, etc. Asimismo, y con el propósito de conocer la opinión de los visitantes, se implementaron encuestas, técnica cuantitativa de recolección de datos que permite establecer una interpelación directa del visitante (Loomis 1987; Pérez Santos 2000; Screven 1990). Para la elaboración de las preguntas se tuvieron en cuenta los resultados de diagnósticos previos, realizados en ediciones anteriores por el equipo de evaluación de público de TECNÓPOLIS (coordinado por el MINCyT). Si bien dichos resultados son insumo interno de los organizadores, fue posible acceder a ellos a través de los contactos establecidos con el Ministerio. Estos indicaron que los visitantes a la megaferia en el 2013 respondían a ciertas características, entre las que se destacan: público de todas las edades; de diversos niveles de estudio (predominantemente secundario) cuyas actividades laborales no están, en su mayoría, vinculadas a las temáticas expuestas. Con respecto a las motivaciones se destaca un alto interés por conocer los avances de la ciencia y la tecnología en Argentina y también la búsqueda de entretenimiento. La mayoría de los visitantes insumen una alta cantidad de horas (5/8) en recorrer TECNÓPOLIS pero, en cada stand permanece un breve lapso de tiempo (MINCyT 2013). Frente a esta información, se decidió elaborar una nueva encuesta ${ }^{6}$ anónima y al azar para aplicar al público de la exhibición "Evolución" (mayor de 18 años). Si bien el diseño de la misma estuvo a cargo de los autores de este trabajo, su implementación la realizó el equipo de evaluación de público de TECNÓPOLIS, quienes se ofrecieron a administrar el cuestionario ya que es un mecanismo que realizan de manera periódica en sus diferentes stands. Así, el muestreo fue realizado a los visitantes de la exposición durante el mes de octubre de 2014. El cuestionario constó de preguntas cerradas (con opciones) y abiertas (Figura 3). La decisión de incluir estas últimas, de diferente sistematización y codificación, responde a que aportan datos cualitativos para la identificación de las opiniones del público. Cabe destacar que muchas de las preguntas realizadas a los visitantes apuntan al mismo tema, pero están formuladas de manera diferente. Esta forma de repreguntar por aspectos similares permite hacer un análisis comparado sobre la satisfacción real, y reducir lo que Pérez Santos (2000) denomina "riesgo de deseabilidad social", común en este tipo de estudios donde los encuestados tienden a responder en positivo acerca de si les gustó o no, para satisfacer la demanda del encuestador.

Para complementar el análisis se recurrió a entrevistas semiestructuradas (Pérez Santos 2000) con el fin de comprender el proceso de montaje, así como la opinión de los organizadores y de algunas de las personas involucradas en su puesta en marcha y desarrollo. Entre los testimonios se incluyen gestores, investigadores y guías para obtener una mirada más integral del caso. Para los gestores se decidió hablar con aquellos que desde el equipo argentino lideraron el proyecto, se trata del coordinador del Área de Control de Gestión del MINCyT en TECNÓPOLIS y el Presidente de la Fundación Félix de Azara (Argentina) quien coordinó el guión y montaje. Para el caso de los guías se seleccionó uno y se lo entrevistó. Su elección al azar se debió a que todos los guías eran arqueólogos capacitados en Argentina por el personal del Museo de la Evolución Humana de Burgos.

\section{La Exhibición y su Mensaje}

Para el análisis se evaluó la organización espacial y su accesibilidad, teniendo en cuenta que la misma fue diseñada para realizar en una visita autoguiada. Esta estrategia es efectiva teniendo en cuenta la variedad y cantidad de propuestas disponibles en TECNÓPOLIS. "Evolución" cuenta con cuatro pabellones conectados entre sí a través de una pasarela al aire libre y, aunque contiguos, cada uno de ellos constituye espacios independientes. Según la tipología de exposiciones propuesta por Fernández y García Fernández (1999) predomina el recorrido mixto, donde se combinan el de tipo estructurado (mediante el uso de vallas externas e internas) y en algunos casos, de tipo sugerido, como en el interior de algunos pabellones (p.ej. "Hombres Modernos y Neandertales"). La accesibilidad física es óptima, mediante el empleo de rampas anchas, sin 


\section{ENCUESTA EVOLUCIÓN EN TECNÓPOLIS}

1. En esta exposición, usted que preferiria:

A. Objetos originales del pasado

B. Dibujos, réplicas y reconstrucciones del pasado

C. Imágenes o esculturas que interpreten el pasado

2. ¿Cree que los textos deben acompañar a los objetos?

A. Sí, pero sólo una descripción del objeto

B. Sí, que me informen en extenso del objeto

C. No, no me gusta leer en las exposiciones

D. No, prefiero los textos a la entrada o a la salida, alejados de los objetos

3. ¿Le gustan en este tipo de exposiciones los apoyos gráícos como los dibujos?
A. No
B. Sí

4. ¿Qué le gusta más?
A. Los fósiles humanos
B. Los instrumentos y los objetos (vivienda, armas, vestimenta)
C. Los animales con el paisaje y las escenas

5. ¿Qué fue lo que más le impactó de la muestra?

6.La muestra le gustó:
A. Mucho
B. Poco
C. Nada

7. ¿Realizó una visita guiada o autoguiada? ¿Notó dificultades?

8. ¿Considera que ha aprendido algo nuevo?

9. ¿Podría indicamos algo que no le ha gustado o con lo que no está de acuerdo?

Figura 3. Encuesta aplicada.

Applied survey.

obstáculos que entorpezcan el recorrido de personas con capacidades motoras diferentes.

En segundo lugar, se evaluó el mensaje que se buscó brindar desde la coordinación general, a través de la museografía de la exposición. Para ello se realizó una comparación entre lo observado en trabajo de campo y lo que según los propios organizadores quisieron exhibir, en sus propias palabras "invitar a reflexionar acerca de la evolución de nuestra propia especie, sobre qué características son las que nos hacen humanos, y de cuándo y cómo las fuimos adquiriendo" (Adrián Giacchino Comunicación personal 2014).

Teniendo en cuenta el objetivo de los organizadores, se evaluó a partir de recorridas y observaciones, la forma de presentar el guión museográfico. En ese sentido se puede señalar que en el primer pabellón de la exposición se expone el origen de la vida en la tierra y el lugar del ser humano en el universo (Big Bang), mediante videos proyectados en diferentes pantallas. La muestra continúa con el pabellón "Evolución Humana", donde se remarcan las principales cualidades y transformaciones anatómicas que han experimentado los homínidos a través de millones de años (locomoción, alimentación, lenguaje, confección de herramientas, etc.) y se presentan las distintas especies que antecedieron al actual Homo sapiens. Esta sala contiene esculturas a escala real que representan a los homínidos en vida y réplicas de los fósiles hallados por los científicos en África, Asia y Europa, acompañadas con algunos textos breves sobre las características "humanas" y réplicas de los restos óseos más representativos de cada especie (Figura 4).

El siguiente pabellón "Hombres Modernos y Neandertales" está destinado a explicar la convivencia, similitudes o diferencias que contribuyeron al éxito de una especie y a la extinción de la otra en Europa. Se destaca una escena de caza de mamut, replicada a tamaño real y una vivienda de neandertales fabricada con huesos de esos mismos animales, donde la nieve cae de forma tal que ambienta la escena de manera real (Figuras 5 y 6). En la cuarta y última sala "El 


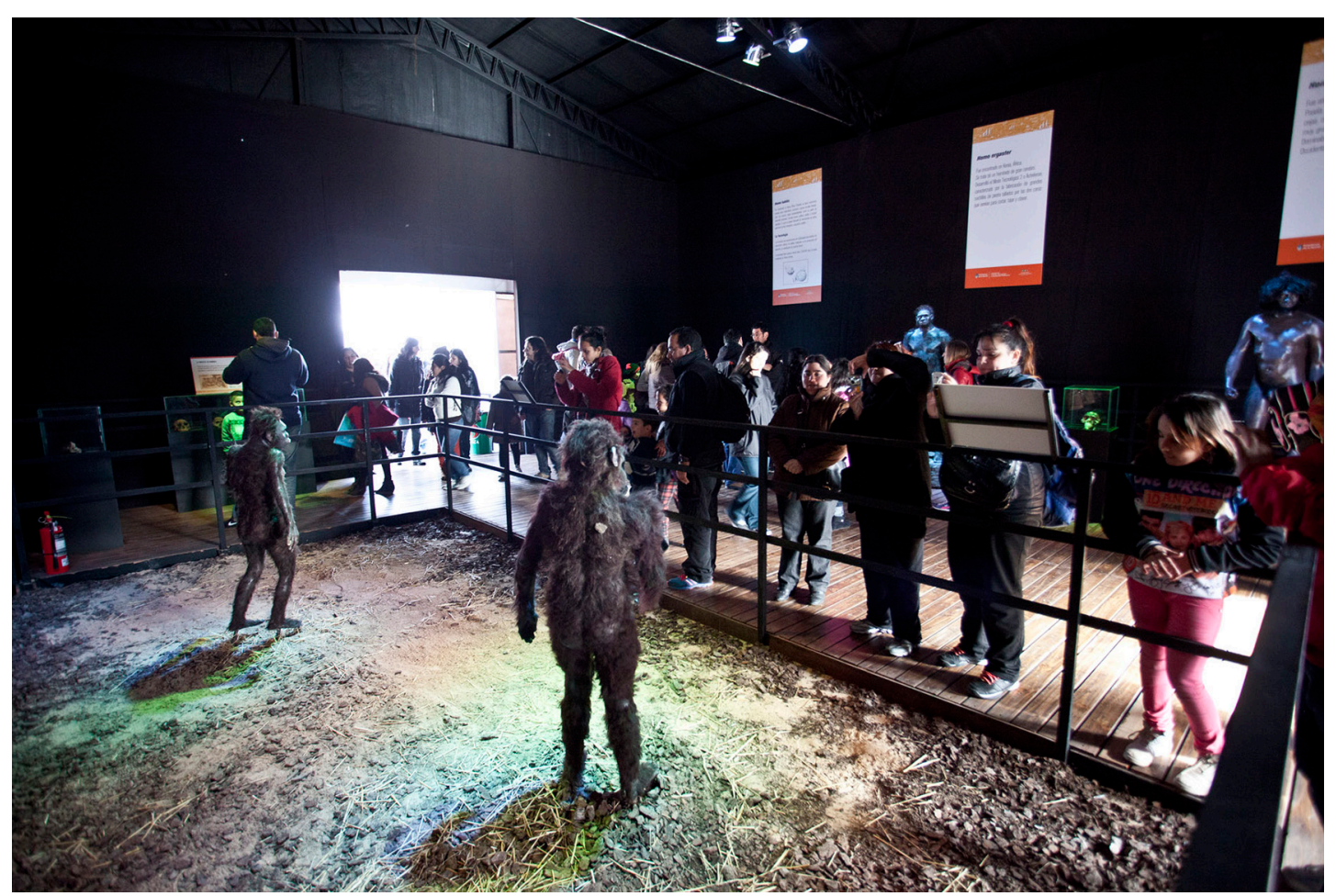

Figura 4. Sala de los homínidos. Gentileza MINCyT.

Hominids room (courtesy of MINCyT).

hombre llega a América", se explica quiénes, cuándo, cómo y por qué llegaron a este territorio (Figura 7). Se sitúan las primeras poblaciones bonaerenses con ejemplos de sitios arqueológicos de la provincia de Buenos Aires y se expone un fósil original de gliptodonte, megamamífero sudamericano que se extinguió hace aproximadamente 8.500 años y convivió con los seres humanos (Figura 8). En estos tres pabellones la ambientación especial conjuga el uso del color, la iluminación y otros efectos escenográficos para recrear una atmósfera contextual. Las paredes son de color negro y la iluminación artificial destaca solo las escenas, neutralizando cualquier aspecto ajeno y dando protagonismo exclusivo a los objetos expuestos. Asimismo, los textos que acompañan a las réplicas de fósiles u homínidos son breves y descriptivos, mientras que los que complementan la información general del pabellón son explicativos (Figura 9). Así, las escenas e imágenes son protagonistas.

En términos generales, según las observaciones realizadas, se puede plantear que el mensaje principal de la exhibición efectivamente alude a resaltar las características biológicas y culturales que se fueron adquiriendo durante millones de años, por lo tanto se corresponde con parte del objetivo planificado por los organizadores. No obstante, en la exposición no se encontraron elementos directamente vinculados con el propósito de "invitar a reflexionar" sobre este complejo proceso (primera parte del objetivo expresado por el coordinador).

Con respecto al mensaje comunicado, se puede destacar que existe una diferencia entre la sala introductoria y las tres restantes. En la primera se utilizan dispositivos tecnológicos (televisor) donde se presentan imágenes del origen del planeta y de la vida, apelando a un relato meramente conceptual. Por el contrario, los tres pabellones siguientes están montados sobre la base de una fuerte escenografía realista que apela a las reproducciones de escenas y dibujos con un enfoque que busca dar una visión global y ambiental de la evolución humana. De este modo, se observan dos formas diferentes de presentar la información que genera una aparente discontinuidad entre todas las salas.

\section{La Opinión de los Visitantes}

Para realizar este estudio se encuestó a 392 visitantes (ambos sexos y mayores de edad) de 


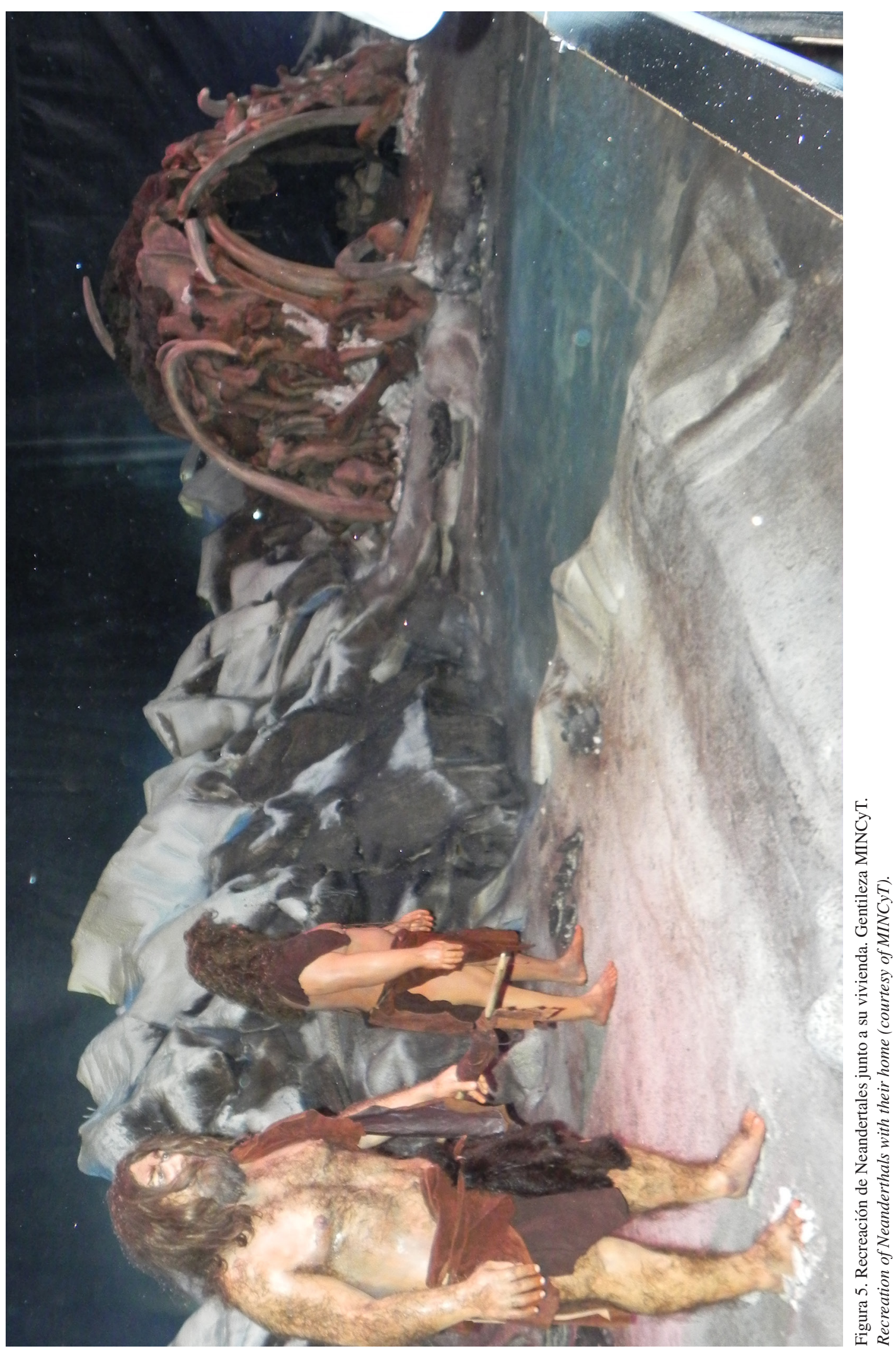




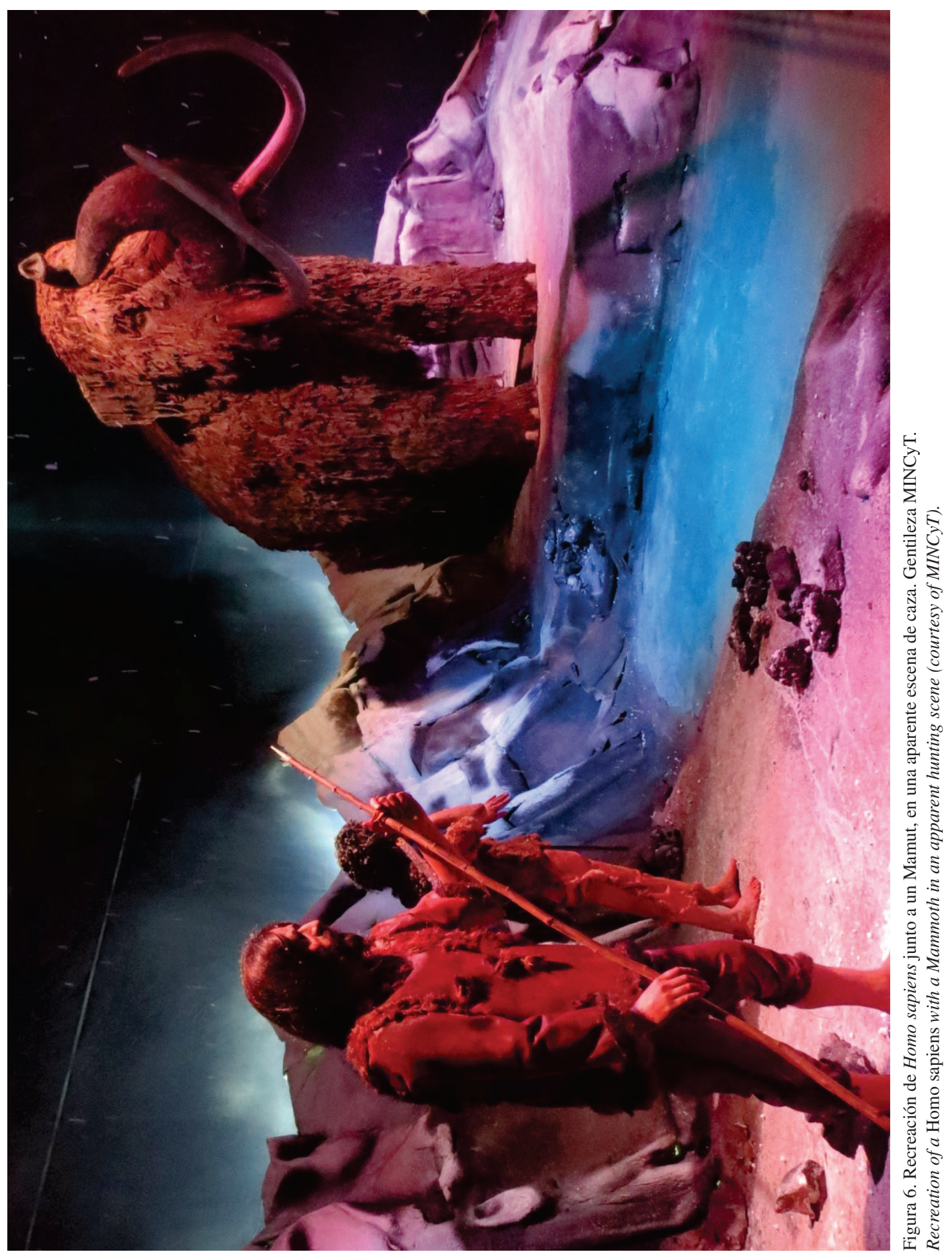




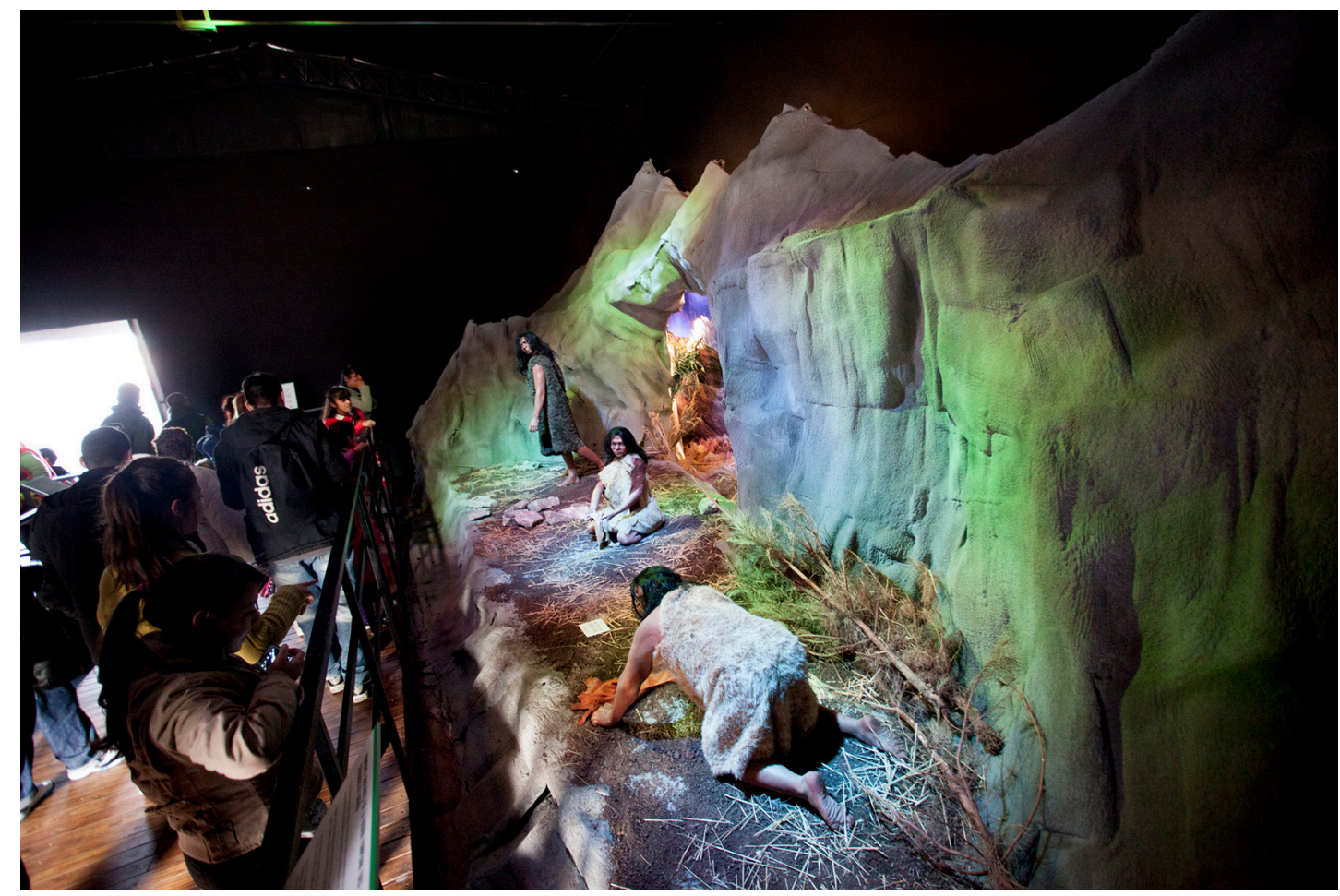

Figura 7. Escena de humanos en América. Gentileza MINCyT. A scene of humans in America (courtesy of MINCyT).

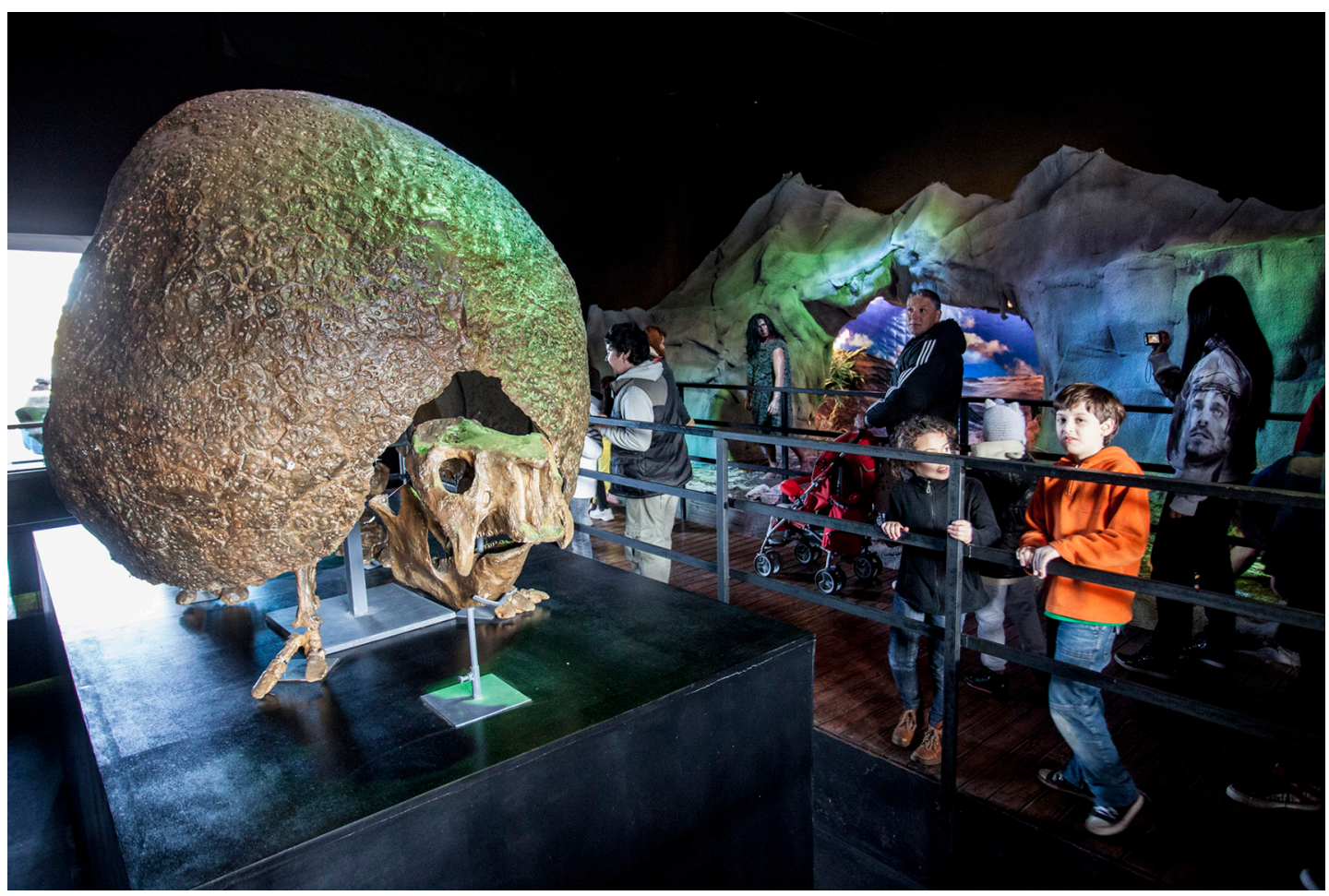

Figura 8. Fósil original de gliptodonte. Gentileza MINCyT. Original Fossil gliptodonte (courtesy of MINCyT). 


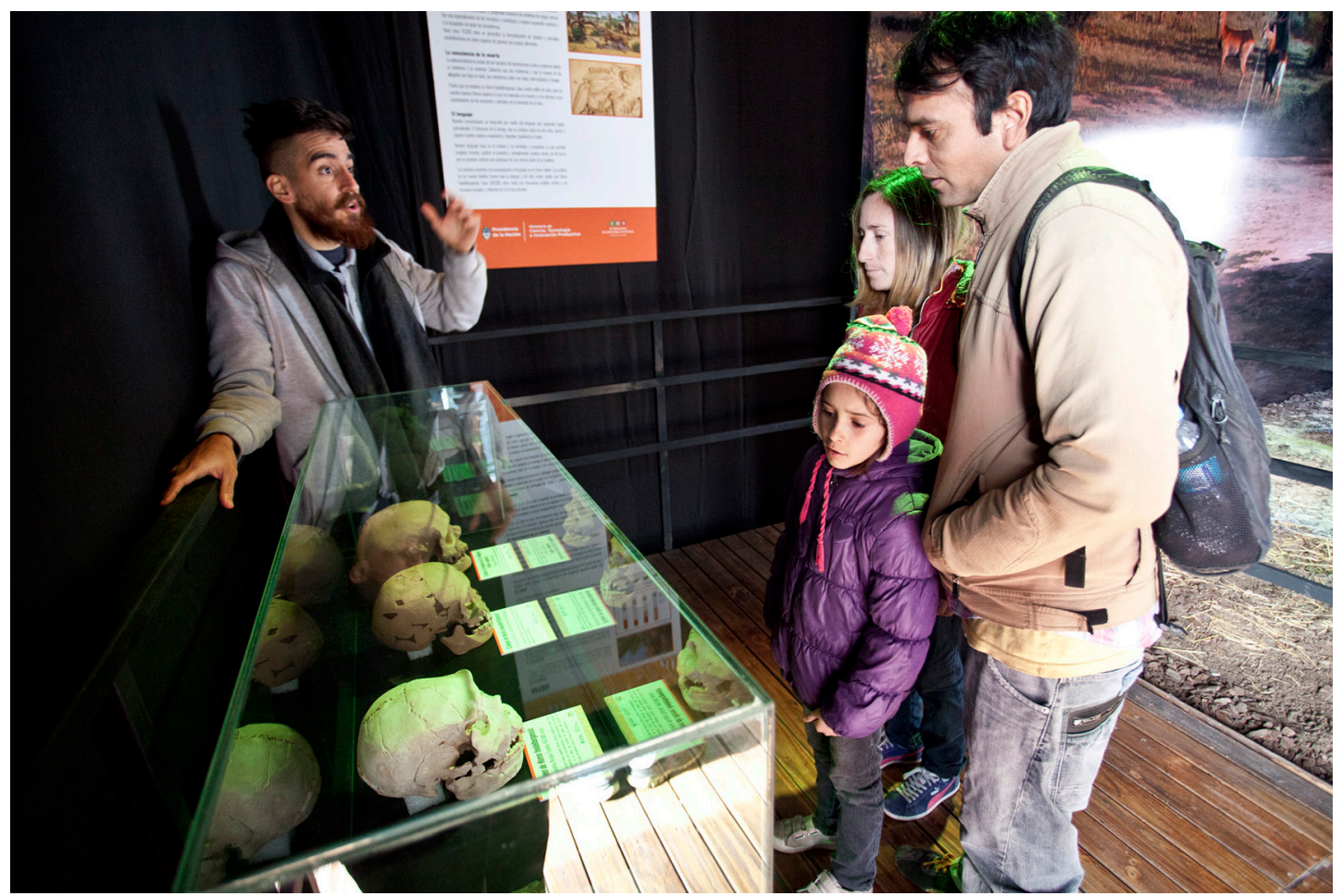

Figura 9. Vitrinas con réplicas. Gentileza MINCyT.

Showcases with replicas (courtesy of MINCyT).

la exposición "Evolución”. En función de los resultados obtenidos, en primer lugar se presentarán aquellos referidos a sus gustos y preferencias y posteriormente los correspondientes a la interpretación del mensaje.

En ese sentido, hay que señalar el alto porcentaje de respuestas positivas frente a la pregunta cuánto le gustó la muestra (ver síntesis de respuestas a preguntas cerradas en Figura 10). El 77\% afirma "mucho". Este resultado se apoya con el obtenido en relación con la pregunta abierta sobre si hubo algo que no le gustó o con lo que no esté de acuerdo: casi $60 \%$ responde "nada" (Figura 11). La mayoría del $40 \%$ restante, señala que no le gustó la introducción (origen del planeta y la vida). Esto podría dar cuenta de que los visitantes no han considerado pertinente el esquema propuesto por los organizadores de la exposición.

Por otro lado, ante la pregunta abierta sobre qué fue lo que más le impactó, los encuestados responden de manera diversa (Figura 12). Para su análisis se construyeron categorías a partir de los nombres de cada uno de los pabellones que permiten englobar parte de esta multiplicidad de opiniones. En primer lugar señalan los elementos del pabellón "Hombres Modernos y Neandertales", le siguen en orden decreciente los de "Evolución Humana" y por último, aquellos propios de "El hombre llega a América". Esto podría deberse a que fósiles "humanos" tan diferentes a los conocidos resultarían novedosos y de alto impacto visual.

Otra cuestión a resaltar es sobre los soportes que acompañan el relato. Frente a la pregunta referida a si los textos deben acompañar a los objetos, una amplia mayoría respondió afirmativamente (328 respuestas, 84\%) aunque difieren entre los que consideran que ese texto debe ser solo una descripción del objeto (188) y los que creen que la información debería ser más extensa (140). Asimismo, ante la consulta sobre los apoyos de tipo gráfico (dibujos) a la mayoría les "gustan". Cuando se les interpela sobre qué les gusta más, casi el $60 \%$ responde fósiles humanos, le sigue en orden decreciente los animales con el paisaje y las escenas. Retomando los aspectos que no les han gustado o con los que menos están de acuerdo, un mínimo de respuestas $(4,5 \%)$ aluden a la ausencia de folletos, mapas, gráficos y líneas de tiempo; es 


\begin{tabular}{|c|c|c|c|c|c|c|c|c|c|c|c|c|}
\hline \multicolumn{2}{|l|}{ Preguntas Cerradas } & & \multicolumn{10}{|c|}{ Ver Figura 3 para ampliar conformación de las preguntas } \\
\hline \multirow{2}{*}{\multicolumn{2}{|c|}{$\begin{array}{l}\text { P1. En esta exposición, } \\
\text { usted qué preferiría: }\end{array}$}} & & A & B & c & Ау B & $\mathrm{AyC}$ & A, By C & By C & \multicolumn{2}{|c|}{ Otras Respuestas } & No Responde \\
\hline & & & 170 & 107 & 88 & 7 & 5 & 6 & 2 & \multicolumn{2}{|l|}{6} & 1 \\
\hline \multirow{2}{*}{\multicolumn{2}{|c|}{$\begin{array}{l}\text { P2. ¿Cree que los textos } \\
\text { deben acompañar a los objetos? }\end{array}$}} & A & в & c & D & AyB & AyC & Ay & \multicolumn{2}{|c|}{ By D } & No Responde & \\
\hline & & 183 & 136 & 53 & 12 & 3 & 1 & \multicolumn{2}{|c|}{1} & \multicolumn{2}{|r|}{2} & \\
\hline \multirow{2}{*}{\multicolumn{7}{|c|}{$\begin{array}{l}\text { P3. ¿Le gustan en este tipo de exposiciones los apoyos } \\
\text { gráficos, como los dibujos? }\end{array}$}} & A & \multicolumn{2}{|r|}{ B } & AyB & \multicolumn{2}{|c|}{ No Responde } \\
\hline & & & & & & & 40 & \multicolumn{2}{|c|}{348} & 1 & \multicolumn{2}{|l|}{3} \\
\hline \multirow[t]{2}{*}{ P4. ¿Qué le gusta más? } & A & в & \multicolumn{2}{|l|}{ C } & A $\mathrm{yB}$ & A, By C & $\mathrm{AyC}$ & \multicolumn{2}{|c|}{ ByC } & No Responde & & \\
\hline & 126 & 65 & 152 & & 4 & 28 & 9 & \multicolumn{2}{|r|}{4} & 4 & & \\
\hline \multirow{2}{*}{\multicolumn{2}{|c|}{ P6. La muestra le gustó: }} & & Mucho & & \multicolumn{3}{|c|}{ Poco } & \multicolumn{2}{|c|}{ Nada } & \multicolumn{2}{|c|}{ No Responde } & \\
\hline & & \multicolumn{3}{|c|}{303} & \multicolumn{2}{|r|}{47} & & \multicolumn{2}{|c|}{6} & \multicolumn{2}{|r|}{36} & \\
\hline \multirow{2}{*}{\multicolumn{5}{|c|}{$\begin{array}{l}\text { P7. ¿Realizó una visita guiada o autoguiada? } \\
\text { ¿Notó dificultades? }\end{array}$}} & \multicolumn{2}{|c|}{ Autoguiada } & Guiada & & \multicolumn{2}{|c|}{ No Responde } & & \\
\hline & & & & & \multicolumn{2}{|c|}{270} & 84 & & 38 & & & \\
\hline
\end{tabular}

Figura 10. Síntesis de respuestas a preguntas cerradas.

Synthesis of answers to closed questions.

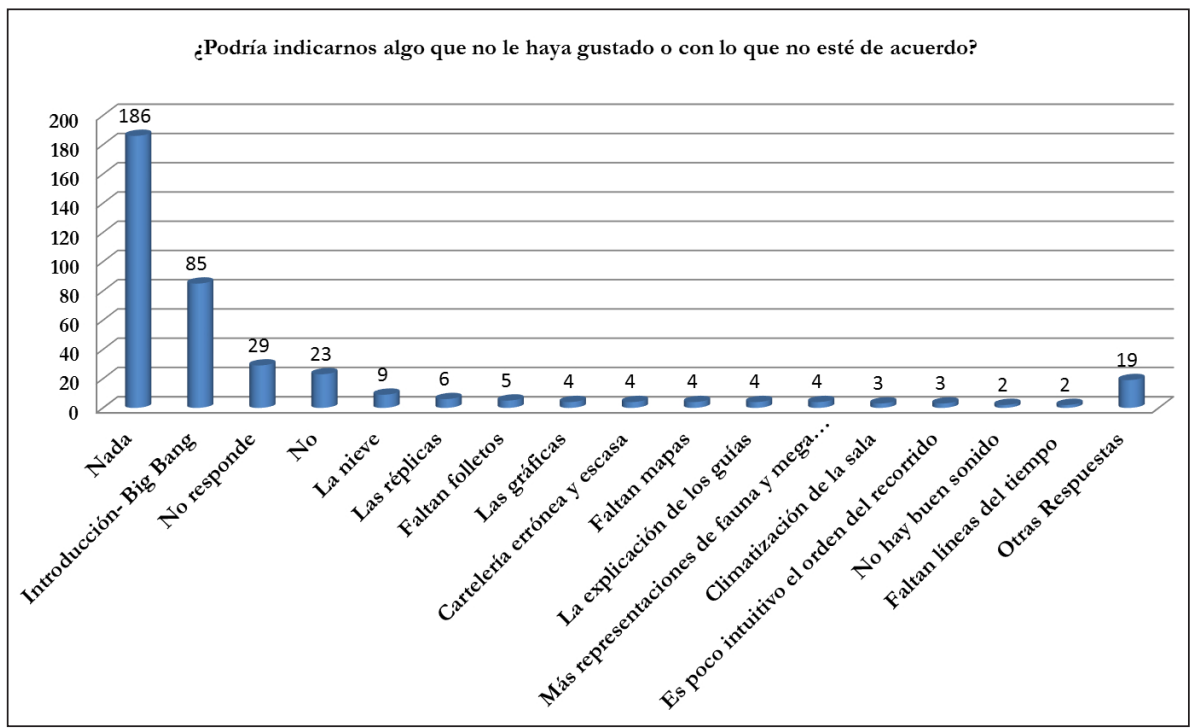

Figura 11. Respuestas “¿Podría indicarnos algo que no le ha gustado o con lo que no está de acuerdo?”. Answers to "Could you mention something you did not like or do not agree with?".

decir, recursos visuales considerados didácticos porque requieren menor esfuerzo sin resignar eficacia. Esta cuestión también fue puntualizada por uno de los guías de la exhibición al ser consultado sobre algún aspecto que considere ausente en la misma: "Me gustan los mapas, porque lo visual ayuda a resumir. Por ejemplo tener el ingreso a América en un mapa resolvería lo abstracto del recorrido" (Fernando Cabrera comunicación personal 2014). Si sumamos que la muestra está diseñada para una visita autoguiada y efectivamente el $76 \%$ de los visitantes no optó por la explicación de un guía, la incorporación de este tipo de recursos significaría un aporte a la comprensión de contenidos. 


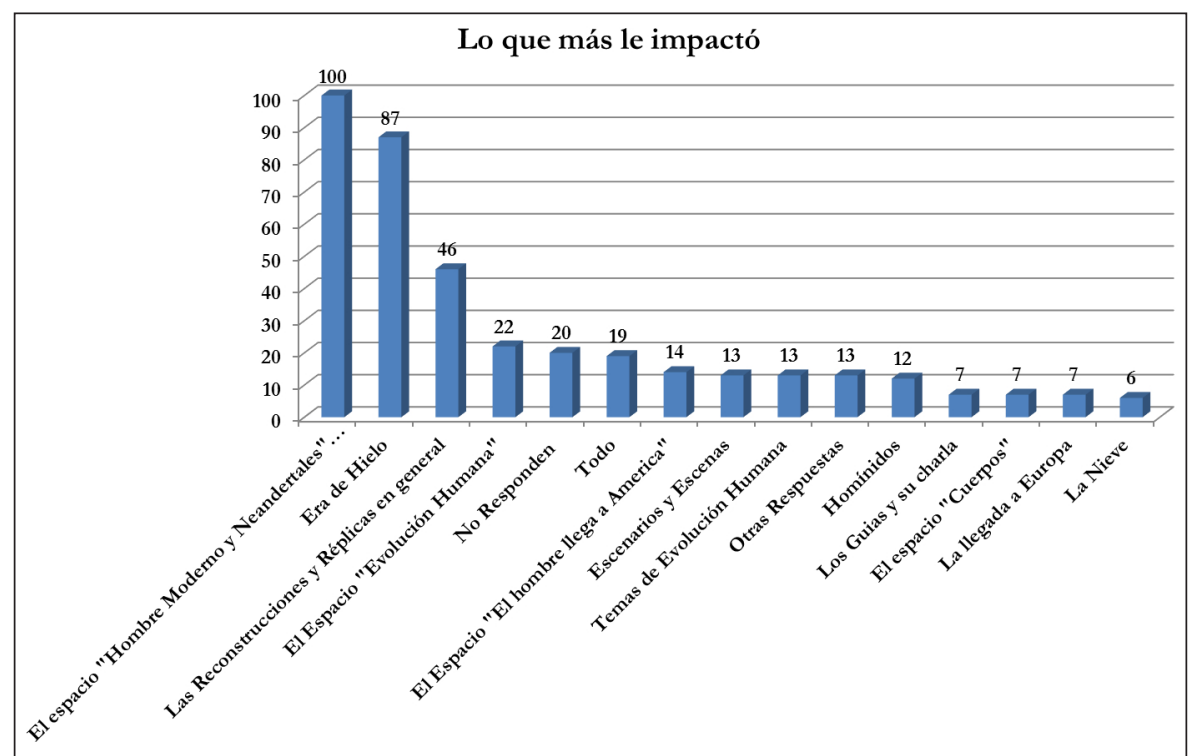

Figura 12. Respuestas “¿Qué fue lo que más le impactó de la muestra?”.

Answers to "What struck you most about the exhibit?".

Un segundo aspecto que se intentó evaluar es la interpretación de la información por parte de los visitantes, para lo que se realizó la pregunta: “¿Considera que ha aprendido algo nuevo?”. La intención de la misma fue explorar lo novedoso de los contenidos, advertir hasta qué punto la experiencia les resultó enriquecedora y conocer qué aspectos de la temática científica expuesta eran poco conocidos o desconocidos por ellos. Los visitantes manifiestan haber aprendido sobre diversos temas: evolución, homínidos, llegada a América o fauna/megafauna (Figura 13). Respuestas, en cierta forma, acordes con el objetivo de la exhibición, que busca mostrar la evolución de la humanidad.

En general se puede plantear que los visitantes valoraron positivamente que en un contexto como TECNOPÓLIS se sintieran interpelados por la exposición "Evolución". En este sentido manifiestan agrado al ver fósiles y escenas recreadas. Destacan los elementos espectaculares (edad del hielo, con el mamut y la nieve) (Figura 14), las dualidades que simplifiquen las comparaciones (neandertales /sapiens), y se muestran menos atraídos con la introducción (Big Bang).



Figura 13. Respuestas “¿Considera que ha aprendido algo nuevo?”.

Answers to "Do you think you have learned something new?". 


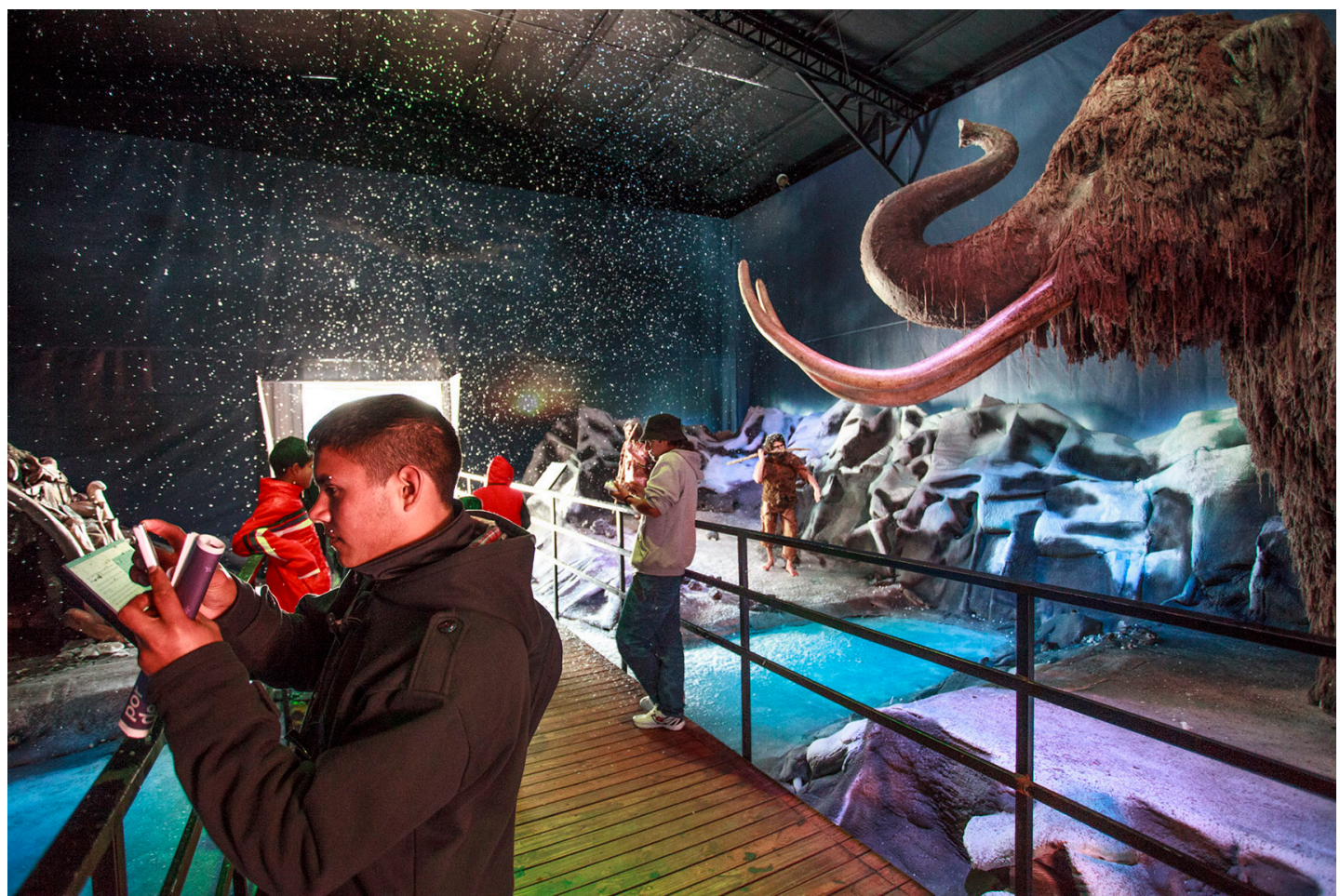

Figura 14. Escenografía con efecto nevado. Gentileza MINCyT. Set with snow effect (courtesy of MINCyT).

En palabras del guía, una de las principales cuestiones a aclarar durante las visitas es la idea de que los humanos en sus inicios "no eran monos", enfatizando que con los monos actuales se comparten ancestros. Asimismo, se manifiesta que más allá de adaptar cada visita al interés que demuestre el grupo, se busca hacer foco en las evidencias más tempranas de manifestaciones simbólicas y de la consciencia de la muerte, cuestiones primordiales para definir "lo que nos hace humanos".

De las cuestiones más consultadas por los visitantes a los guías se puede señalar, también, algunos puntos que podrían ser insumos para posibles reediciones de la muestra: suele llamar la atención por qué la desnudez o el uso de vestimenta entre las distintas especies. Asimismo, cuando reciben alguna consulta acerca de la visión creacionista de la humanidad, los guías hacen hincapié en que esta exhibición se basa en la explicación científica y que no tiene interés en entrar en confrontación con concepciones religiosas. En relación a esto, sin embargo cabe destacar que tan solo uno de los 392 encuestados manifiesta estar en desacuerdo con la teoría evolutiva.

\section{Discusión}

La combinación del análisis del guión y de la museografía empleada con la opinión de los visitantes y diferentes actores sociales implicados en la puesta en escena de esta exposición, permite señalar tres cuestiones principales que incluyen fortalezas y debilidades.

En primer término, se afirma que la comunicación a través de la exhibición se ha producido (Neresini y Pellegrini 2008), dado que los visitantes reconocen identificar temáticas novedosas tales como los diferentes homínidos, la fauna y megafauna, el poblamiento americano, entre otros. Sin embargo, queda pendiente saber si lograron comprender estos conceptos, poco frecuentes en la vida cotidiana o si bien están respondiendo en los términos de lo que Pérez Santos (2000) denomina deseabilidad social. Aquí resulta necesario señalar que esta investigación es susceptible de profundizarse en el futuro, implementando técnicas cualitativas como las entrevistas en profundidad, los grupos de discusión focal y la observación participante que permitan identificar la comprensión de contenidos. 
Asimismo, el diseño experimental, consistente en comparar la situación del visitante previo a la exhibición (evento comunicativo) con la situación a posteriori, a través de cuestionarios (Neresini y Pellegrini 2008).

En segundo lugar, se observa una desconexión entre la sala introductoria, más conceptual y los tres pabellones restantes, donde predomina el realismo. Efectivamente, según las encuestas, los visitantes se sienten más atraídos por estas tres salas donde se utilizan las representaciones y reconstrucciones a escala y apariencia real, cuestión que ha sido resaltada también en otros estudios sobre evolución. Por ejemplo Endersby (1997:194) menciona que la estrategia de que los homínidos parezcan "respirar y parpadear" es un poderoso dispositivo retórico. Sin dudas, las soluciones iconográficas tienen gran poder didáctico porque dan información esencial y rápida sobre determinados objetos, tales como el aspecto de una especie de homínido (Hernández Cardona 2001). En este sentido, "Evolución" sería más eficaz en su mensaje sin la propuesta de la primera sala, lo que implicaría una reestructuración en futuras ediciones.

En tercer lugar, en relación con la utilización política de las teorías evolucionistas a lo largo de la historia de los últimos dos siglos, resulta oportuno afirmar que en la muestra "Evolución" no se observan contenidos que reproduzcan un sesgo ideológico que pueda ser identificado con el evolucionismo cultural de los siglos XIX y XX. En otro plano, pero vinculado a estas teorías, es importante destacar que actualmente en otros países, como por ejemplo Estados Unidos, estas exhibiciones se tienen que enfrentar a la oposición del público, más adepto a las ideas creacionistas (Stein y Storksdieck 2005). Para este caso analizado no se manifestaron objeciones. Una posible interpretación es que en Argentina la educación es laica (además de pública y gratuita) y, a pesar de existir una cantidad importante de cristianos y católicos, no hay imposiciones religiosas. De hecho, las teorías científicas evolutivas se insertan en espacios curriculares de la educación básica que posibilitan su difusión, aceptación y consenso.

\section{Comentarios Finales}

En este trabajo se presentó un caso particular de Argentina sobre una exposición de evolución humana en un contexto de características masivas y excepcionales. Las políticas implementadas por el Estado nacional durante el período 2003-2015 buscaron claramente posicionar a Argentina a nivel mundial en CyT. Esto implicó una importante inversión económica en materia de promoción de la investigación, y también un correlato en su amplia difusión. En este sentido se podría plantear la intencionalidad política que subyace en la creación de una exposición como TECNÓPOLIS, con la que el gobierno buscó legitimarse y jerarquizar su gestión en el imaginario social. En la misma línea, la decisión de traer desde el exterior la muestra "Evolución" responde a una estrategia que no solo tuvo como fin profundizar y dar a conocer una temática, estudiada en Argentina pero desarrollada con mayor profundidad en otros países, sino además establecer alianzas con prestigiosos referentes a nivel mundial. Así se supieron aprovechar las potencialidades de cada región en un proyecto común y donde cada país aportó elementos significativos para la temática a exhibir y asumió el desafío de comunicar una prehistoria evolutiva que fue compartida colectiva y globalmente.

Posteriormente, en este trabajo se realiza una comparación con las grandes exposiciones universales que se realizaron en el siglo XIX, presentando similitudes y diferencias. Se marcaron también una serie de reflexiones generales en torno a las implicancias sociales de los mensajes que comunican los museos y se enfatizó sobre la utilización política de las teorías evolucionistas a lo largo de los últimos dos siglos.

En este trabajo se abordó una experiencia de CPC desde un estudio de público que se articuló con un análisis del mensaje de la exhibición. Sobre este punto es necesario señalar que dicha investigación es susceptible de profundizarse por medio de otras técnicas. En esta primera aproximación se realizó el análisis del guión y de la museografía y de la opinión de los visitantes mediante la implementación de encuestas. La combinación de herramientas posibilitó un diagnóstico a partir del cual esbozar contribuciones para los estudios de percepción pública de la ciencia (Cortassa 2011). Las entrevistas no han sido aplicadas para interpelar al público, sino para comprender la exposición y recoger la voz de los distintos actores involucrados en vistas a una mirada más integral de la exhibición.

En síntesis, consideramos que los resultados permiten arribar a un panorama general sobre las fortalezas de la exhibición, así como de aquellos 
aspectos susceptibles de mejora. Constituye un análisis preliminar de los gustos y preferencias del público o de su grado de satisfacción, permitió efectuar inferencias e interpretaciones respecto de cómo se han relacionado los visitantes con los contenidos sobre evolución humana que le fueron presentados. Estas conclusiones permiten afirmar que la compleja trama de la evolución humana no les ha resultado indiferente.

Agradecimientos: A los evaluadores del trabajo por sus sugerencias. Al Dr. Tomás Ameigeiras, coordinador en TECNÓPOLIS del Área de Control de Gestión del MINCyT y a todo su equipo, por permitirnos realizar el estudio, facilitar la tarea y colaborar en la implementación de la encuesta en la exhibición "Evolución". Al Dr. Adrián Giacchino, presidente de la Fundación Félix de Azara (Argentina), por ceder su testimonio y colaborar con material referente a la exposición. Al guía de la exposición por ceder su testimonio. Asimismo queremos agradecer la lectura y sugerencias recibidas durante la elaboración de este artículo por el Dr. Rafael Curtoni y la Mag. Mirta Bonnin, sin embargo las ideas expresadas en el mismo son responsabilidad de los autores. Este trabajo fue realizado y financiado en el marco de la Beca Posdoctoral Erasmus Mundus Sud-UE de la Dra. María Eugenia Conforti en el Área de Prehistoria de la Universidad de Burgos (España).

\section{Referencias Citadas}

Albornoz, M. y A. Gordon 2011. La política de ciencia y tecnología en Argentina desde la recuperación de la democracia (1983-2009). En Trayectorias de las Políticas Científicas y Universitarias de Argentina y España, editado por M. Albornoz y J. Sebastián, pp. 67-122. CSICS, Madrid.

Alegría Luicime, L. 2004. Museos y campo cultural. Patrimonio indígena en el Museo de Etnología y Antropología de Chile. Conserva 8:57-70.

Alonso Fernández, L. e I. García Fernández 1999. Diseño de Exposiciones. Concepto, Instalación y Montaje. Alianza editorial, Madrid.

Althusser, L. 1971. Ideología y Aparatos Ideológicos de Estado. Freud y Lacan. Nueva Visión, Buenos Aires.

Bourdieu, P. y A. Darbel 2004. El Amor al Arte. Los Museos Europeos y su Público. Paidós, Buenos Aires.

Cortassa, C. 2011. La Ciencia ante el Público. Dimensiones Epistémicas y Culturales de la Comprensión Pública de la Ciencia. Eudeba, Buenos Aires.

Einsiedel, E. 2007. Editorial: Of publics and science. Public Understanding of Science 16:5-6.

Durrans, B. 1988. The future of the others: Changing cultures on display in ethnographic museums. En The Museum TimeMachine. Putting Culture on Display, editado por R. Lumley, pp. 143-176. Routledge, Londres - Nueva York.

Endersby, J. 1997. The evolving museum. Public Understanding of Science 6 (2):185-206.

Falk, J. y L. Dierking 2000. Learning from Museums. Visitors, Experiences and the Making of Meaning. Altamira Press, Londres.

Fayard, P. 2004. La Comunicación Pública de la Ciencia. Hacia la Sociedad del Conocimiento. UNAM, México, D.F.

Fernández Polcuch, E., A. Bello y L. Massarani 2016. Políticas Públicas e Instrumentos para el Desarrollo de la Cultura
Científica en América Latina. Estudios y Documentos de Política Científica de ALC. UNESCO, Montevideo.

Foucault, M. 1996. Las Palabras y las Cosas: una Arqueología de las Ciencias Humanas. Siglo XXI, Barcelona.

García Blanco, A. 1999. La Exposición, un Medio de Comunicación. Ediciones Akal, Madrid.

Gregory, J. y S. Miller 1998. Science in Public. Communication, Culture and Credibility. Plenum, Londres.

Hernández Cardona, F. 2001. Iconografía didáctica y hominización. Revista IBER 29:53-66.

Hernández Hernández, F. 1998. El Museo como Espacio de Comunicación. Ediciones Trea, Gijón.

Hernández Hernández, F. 2015. Introducción. La Museología: entre la tradición y la posmodernidad. Complutum 26:9-26.

Huyssen, A. 2002. En Busca del Futuro Perdido. Cultura y Memoria en Tiempos de Globalización. Goethe Institut, Fondo de Cultura Económica, México, D.F.

Laumounier, I. 1993. Museo y Sociedad. Centro de Estudios de América Latina, Buenos Aires.

Loomis, R. 1987. Museum Visitor Evaluation: New Tool for Management. American Association for State and Local History, Nashville.

López Ocón Cabrera, L. 2002. La América Latina en el escenario de las exposiciones universales del siglo XIX. Procesos, Revista Ecuatoriana de Historia 18:103-126.

Mac Fadden, B. 2008. Evolution, museums and society. Trends in Ecology \& Evolution 23 (11):589-591.

Merriman, N. 1991. Beyond the Glass Case: The Past, the Heritage and the Public in Britain. Leicester Press, Leicester.

Merriman, N. 2000. The crisis of representation in archaeological museums. En Cultural Resources Management in Contemporary 
Society. Perspectives on Managing and Presenting the Past, editado por F. McManamon y A. Hatton, pp. 300-309. Routledge, Londres.

MINCyT 2013. TECNÓPOLIS General. Manuscrito en posesión del autor.

Neresini, F. y G. Pellegrini 2008. Evaluating public communication of science and technology. En Handbook of Public Communication of Science and Technology, editado por M. Bucchi y B. Trench, pp. 237-251. Routledge, London.

Pawlukiewicz, J., Z. Doering y K. Paasch 1990. Views from the Audience. Planning a new exhibition on human evolution. Current Trends in Audience Research and Evalution. Poster presentado en Visitor Research and Evaluation Committee. Washington, D.C.

Pérez Gollán, J. y M. Dujovne 1996. El Museo Etnográfico: funciones y balance de una experiencia. Runa, Archivo para las Ciencias del Hombre XXII:119-131.

Pérez Santos, E. 2000. Estudios de Visitantes en Museos. Metodología y Aplicaciones. Ediciones Trea, Gijón.

Podgorny, I. y M. Lopes 2008. El Desierto en una Vitrina. Museos e Historia Natural en la Argentina, 1810-1890. Limusa, México, D.F.

Politis, G. y R. Curtoni 2011. Archaeology and Politics in Argentina during the Last 50 Years. En Comparative Archaeologies: A Sociological View of the Science of the Past, editado por L. Lozny, pp. 495-525. Springer Science+Business Media, New York.
Preucel, R. e I. Hodder 1996. Constructing Identies. En Contemporary Archaeology in Theory, editado por R. Preucel e I. Hodder, pp. 601-614. Blackwell, Oxford.

Reca, M. 2016. Antropología y Museos. Un Diálogo Contemporáneo con el Patrimonio. Biblos, Buenos Aires.

Rinesi, E. 2011. Museos, Arte e Identidad. Artesanías en la idea de Nación. Editorial Gorla, Buenos Aires.

Screven, C. 1990. Uses of evaluation before, during and after exhibit design, ILVS Review. Journal of Visitor Behaviour 1 (2):36-66.

Shärer, M. 2000. Le Muséeetl'Exposition: Variation de Langages, Variation de Signes. ICOM, París.

Spiegel, A., E. Evans, W. Gram y J. Diamond 2006. Museum visitors' understanding of evolution. Museums \& Social Issues 1 (1):69-86.

Stein, J. y M. Storksdieck 2005. Life Changes Museum Visitor Survey: Summary of Results. Institute for Learning Innovation, Annapolis.

Trigger, B. 1989. A History of Archaeological Thought. Cambridge University Press, Cambridge.

Vergo, P. (ed.) 1989. The New Museology. Reaktion Books, Wiltshire.

Von Foerster, H. 1981. Observing Systems: Selected Papers of Heinz von Foerster. Inter Systems Publications, Seaside.

\section{Notas}

1 "Bases para un Plan Estratégico de Ciencia 2005-2015", "Plan Estratégico Nacional Bicentenario 2006-2010" y "Argentina Innovadora. Plan Nacional de Ciencia, Tecnología e Innovación 2020".

2 Edición 2012: "Energía para transformar", Edición 2013: "El desafío del conocimiento", Edición 2014: "Un mundo por descubrir" y Edición 2015: "El futuro para siempre".

3 Este estudio que se presenta es de carácter independiente respecto de los organizadores de la exhibición "Evolución" y forma parte de un proyecto de investigación mayor denominado Public Communication of Archaeology and Archaeological Heritage, financiado por la Comunidad Económica Europea en el marco de una beca posdoctoral Erasmus, ejecutada por una de las autoras (M. Conforti) en la Universidad de Burgos, entre 2014 y 2015 y dirigida por el investigador español C. Diez Fernández Lomana. El interés por analizar la exhibición de TECNÓPOLIS surge de la vinculación establecida entre las instituciones involucradas indirectamente en dicho proyecto Erasmus. Conforti, en el marco del mencionado proyecto realizó un estudio de público en el Museo de la Evolución Humana de Burgos, sobre su exposición permanente, por lo que le resultó de interés analizar una muestra inspirada en los contenidos de evolución humana y asesorada por el equipo español, en un contexto de exposición diferente, en Argentina. Para ello se decidió la realización del estudio con la colaboración de especialistas de ambos países.

4 En 2014 TECNÓPOLIS estuvo abierta entre el 18 de junio y el 2 de noviembre, fue visitada por 4.748 .000 personas y presentó un total de 107 stands (Fuente MINCyT).
5 La Fundación de Historia Natural Félix de Azara es una institución no gubernamental y sin fines de lucro, tiene por misión contribuir al estudio y la conservación del patrimonio natural y cultural argentino. Planifica, desarrolla y auspicia exhibiciones para la educación de las ciencias en Argentina y otros países. Desde 2011 participa en el desarrollo de distintas exhibiciones de TECNÓPOLIS. Para el caso de las instituciones españolas, todas conforman un conglomerado asociado a los Yacimientos Arqueopaleontológicos de Atapuerca, en Burgos. En dicho sitio se encuentra un conjunto de hallazgos excepcionales para la investigación de la evolución humana en la Península Ibérica (Patrimonio de la Humanidad UNESCO). La importancia creciente que adquirieron los hallazgos llevó a la Administración de la Comunidad de Castilla y León a crear el "Sistema Atapuerca, Cultura de la Evolución”, liderado por el Museo de la Evolución Humana. Las mismas se asocian con otras instituciones (Universidad de Burgos y Fundación Atapuerca) para difundir el Proyecto Arqueológico Atapuerca.

6 El diseño del cuestionario estuvo a cargo de investigadores de la Universidad de Burgos y la UNICEN. Se trata de un equipo interdisciplinario conformado por dos arqueólogos (uno español especializado en temas de evolución humana y una argentina abocada a la investigación de la arqueología pública y los museos), una antropóloga social con experiencia en puesta en valor del patrimonio cultural y una comunicadora social cuya especialidad es la comunicación pública de la ciencia, en especial la arqueología. 